\title{
Major dietary patterns and carotid intima-media thickness in Bangladesh
}

\author{
Tyler R McClintock ${ }^{1,2}$, Faruque Parvez ${ }^{3}$, Fen $\mathrm{Wu}^{1}$, Tariqul Islam ${ }^{4}$, Alauddin Ahmed ${ }^{4}$, \\ Rina Rani Paul ${ }^{4}$, Ishrat Shaheen ${ }^{4}$, Golam Sarwar ${ }^{4}$, Tatjana Rundek ${ }^{5}$, Ryan T Demmer 6 , \\ Moise Desvarieux $6,7,8$, Habibul Ahsan ${ }^{9, *}$ and Yu Chen $1, *$ \\ ${ }^{1}$ Departments of Population Health and Environmental Medicine, New York University School of Medicine, 650 First \\ Avenue, New York, NY 10016, USA: '2Division of Urology, Department of Surgery, Brigham and Women's \\ Hospital, Harvard Medical School, Boston, MA, USA: ${ }^{3}$ Department of Environmental Health Sciences, Mailman \\ School of Public Health, Columbia University, New York, NY, USA: ${ }^{4}$ U-Chicago Research Bangladesh, Ltd, \\ Dhaka, Bangladesh: ${ }^{5}$ Department of Neurology, Miller School of Medicine, University of Miami, Miami, FL, \\ USA: ${ }^{6}$ Department of Epidemiology, Mailman School of Public Health, Columbia University, New York, NY, USA: \\ ${ }^{7}$ INSERM, UMR-S 707, Université Pierre et Marie Curie-Paris 6, Paris, France: ${ }^{8}$ École des Hautes Études en \\ Santé Publique, Paris and Rennes, France: ${ }^{9}$ Departments of Health Studies, Medicine and Human Genetics and \\ Comprehensive Cancer Center, The University of Chicago, 5841 South Maryland Avenue, Suite N102, Chicago, \\ IL 60637, USA
}

Submitted 1 April 2014: Final revision received 16 February 2015: Accepted 25 February 2015: First published online 11 May 2015

\begin{abstract}
Objective: Carotid intima-media thickness (IMT) is a validated surrogate marker of preclinical atherosclerosis and is predictive of cardiovascular morbidity and mortality. Research on the association between IMT and diet, however, is lacking, especially in low-income countries or low-BMI populations.

Design: Cross-sectional analysis. Dietary intakes were measured using a validated, thirty-nine-item FFQ at baseline cohort recruitment. IMT measurements were obtained from 2010-2011.

Setting: Rural Bangladesh.

Subjects: Participants ( $n$ 1149) randomly selected from the Health Effects of Arsenic Longitudinal Study, an ongoing, population-based, prospective cohort study established in 2000. Average age at IMT measurement was 45.5 years.

Results: Principal component analysis of reported food items yielded a 'balanced' diet, an 'animal protein' diet and a 'gourd and root vegetable' diet. We observed a positive association between the gourd/root vegetable diet and IMT, as each $1 \mathrm{SD}$ increase in pattern adherence was related to a difference of $7 \cdot 74$ (95\% CI $2 \cdot 86$, 12.62) $\mu \mathrm{m}$ in IMT $(P<0 \cdot 01)$, controlling for age, sex, total energy intake, smoking status, BMI, systolic blood pressure and diabetes mellitus diagnoses. The balanced pattern was associated with lower IMT $(-4.95$ (95\% CI -9.78, -0.11) $\mu \mathrm{m}$ for each $1 \mathrm{sD}$ increase of adherence; $P=0 \cdot 045)$.

Conclusions: A gourd/root vegetable diet in this Bangladeshi population positively correlated with carotid IMT, while a balanced diet was associated with decreased IMT.
\end{abstract}

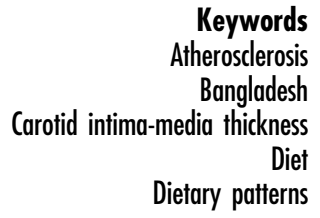

therosclerosis

Bangladesh

Dietary patterns
CVD is the leading cause of death worldwide, although it has been posited that up to $90 \%$ of cases may be preventable simply by modifying diet and lifestyle ${ }^{(1-3)}$. While CVD contributes less, proportionally, to overall mortality in the developing world ( $23 \%$ compared with $\sim 49 \%$ in more economically developed countries), these areas are home to the vast majority of the global population as well as over $60 \%$ of worldwide CVD mortality ${ }^{(4)}$. Additionally, further industrialization stands to yield a decrease in infectious disease mortality and concurrent increase in the burden of $\operatorname{CVD}^{(1,5,6)}$. Hence, as CVD is typically influenced by modifiable lifestyle factors or exposures, it becomes advantageous to recognize risk factors and preclinical markers of disease in populations with varying socio-economic characteristics. This not only facilitates more effective preventive strategies, but also allows for earlier interventions.

Carotid artery intima-media thickness (IMT) is a validated surrogate marker of preclinical atherosclerosis that 
has been shown to predict cardiovascular morbidity and mortality $^{(7)}$. Many studies have sought to examine CVD risk factors in relation to carotid IMT as a mechanistic intermediate. Particularly useful would be a better understanding of how diet, a critical modifiable risk factor for CVD, affects carotid IMT. Previous observational studies have shown high intakes of plant foods and fibre as well as low intakes of saturated fats and processed foods to be inversely associated with carotid $\mathrm{IMT}^{(8-11)}$, while additional experimental studies have tested the effect of dietary or lifestyle interventions on carotid IMT ${ }^{(12-15)}$. More recently, it has been suggested that adherence to a 'Mediterranean' diet may protect against a higher burden of carotid atherosclerotic plaque ${ }^{(16)}$. Data are scarce, however, with respect to comparing whole dietary patterns within a given population ${ }^{(17)}$. Additionally, the vast majority of the aforementioned studies were conducted in Western populations, and little is known about the role of diet in IMT in low-income and low-BMI countries.

In addition to analysing intakes of specific foods or nutrients, evaluation of diet patterns may yield a more comprehensive understanding of how this complex factor affects the aetiology of disease ${ }^{(18)}$. Compared with the 'single nutrient' approach, this method of analysis more fully accounts for interactions between nutrients, as well as interrelationships between dietary components that cause difficulty in distinguishing individual food or nutrient effects $^{(19)}$.

In the present study, we examined the association of major food groups, as well as dietary patterns, with carotid IMT in a rural Bangladeshi population.

\section{Participants and methods}

\section{Study population}

The parent study, Health Effects of Arsenic Longitudinal Study (HEALS), is an ongoing population-based prospective cohort study in Araihazar, Bangladesh ${ }^{(20)}$. Briefly, between October 2000 and May 2002, 11746 men and women ('original cohort') were recruited from a well-defined $25 \mathrm{~km}^{2}$ geographical area, under the criteria that all were married (to reduce loss to follow-up), between 18 and 75 years old and had resided in the study area for at least 5 years. From 2006 to 2008, HEALS was expanded to include an additional 8287 participants ('expansion cohort') following the same methodologies. The overall response rate was $97 \%$. Study participants underwent baseline clinical assessment and structured interviews. Detailed explanations of data collection for such variables as height, weight, smoking status and blood pressure have been published elsewhere ${ }^{(21-23)}$. Informed consent was obtained from study participants; study procedures were approved by the Ethical Committee of the Bangladesh Medical Research Council and the Institutional Review Boards of Columbia University and the University of Chicago.

\section{Assessment of food intake}

Trained interviewers administered a thirty-nine-item FFQ during the baseline assessment. Details of this questionnaire and its validation are available elsewhere ${ }^{(24)}$. Briefly, HEALS investigators worked with local nutrition experts to identify all food items available at the village market in the study area. This formed the basis for a preliminary version of the FFQ to be developed through a series of subsequent extensive discussions with ten focus groups. After pilot testing among 120 local individuals who were not part of the cohort study, trained interviewers completed the FFQ with HEALS participants via in-person interviews. For each food item on the FFQ, participants were queried regarding the amount eaten per meal, as well as the frequency of consumption per day, month and year.

Analysis of 189 respondents randomly selected to complete $7 \mathrm{~d}$ food diaries showed no major differences when compared with data previously obtained in the FFQ (correlation 0.30 to $0 \cdot 76$ ), including common food items, macronutrients and many major micronutrients. This food diary sampling was the largest number possible for the present study, given the financial and logistical constraints of this more intensive form of dietary monitoring. The US Department of Agriculture's Nutrient Database for Standard Reference (abbreviated version) ${ }^{(25)}$ and an Indian food nutrient database ${ }^{(26)}$ were used to convert food intakes to nutrient intake values. Although there is no ideal measure of dietary intakes, food diaries are known to be superior to FFQ and have previously been frequently used to assess the validity of $\mathrm{FFQ}^{(27,28)}$.

\section{Dietary patterns}

From our raw FFQ data, intakes of major food groups were calculated by summing the average daily intake of the relevant individual food items, as listed in Appendix Table 1. Additionally, we have previously described our delineation of three major dietary patterns among participants of in the original cohort ${ }^{(22)}$. Briefly, we performed principal component analysis using the PROC FACTOR procedure in the SAS statistical software package to identify dietary patterns, with an orthogonal rotation (the varimax option in SAS) and conventional criteria including eigenvalue, the scree test, proportion of variance accounted for and the interpretation criterion ${ }^{(29)}$. To avoid any arbitrary decisions on food group definitions, food items were directly entered into the principal component analysis as average daily intakes in grams or millilitres. Each food item received a factor loading associated with each diet pattern, and the factor loading represents the correlation coefficient between the food item and the diet pattern. To indicate a participant's relative standing on each diet pattern in the population, a factor score, which is a linear composite of the optimally weighted food items by factor loadings, was constructed for each dietary pattern. Each participant received a factor score for each identified 
diet pattern. The identification of dietary patterns was conducted separately for the original and expansion cohort, as expansion cohort members were recruited later. The dietary patterns were mostly similar between the two populations (Appendix Table 2). Three major dietary patterns were identified. The 'balanced' pattern was comprised of steamed rice, red meat, fish, fruit and vegetables. An 'animal protein' diet was more heavily weighted towards eggs, milk, red meat, poultry, bread and vegetables. The 'gourd and root vegetable' diet relied heavily on a variety of gourds, radishes, pumpkin, sweet potato and spinach.

We have previously evaluated the associations of these diet patterns in relation to blood pressure at baseline ${ }^{(22)}$, as well as risk of skin lesions ${ }^{(30)}$ and cardiovascular mortality $^{(31)}$.

\section{Assessment of carotid intima-media thickness}

Carotid IMT was measured between April 2010 and September 2011. Eight hundred participants were randomly selected for IMT measurement, from the 11224 original cohort members who provided urine samples at baseline, as part of a previous study on urinary arsenic and $\mathrm{IMT}^{(32)}$. An additional 700 participants were randomly sampled for IMT measurement from the 5136 participants older than 30 years of age in the expansion cohort, as the expansion cohort was, on average, younger. In total, carotid IMT was measured for 1151 individuals, consisting of 575 from the original cohort and 576 from the expansion cohort. A total of 349 participants did not complete IMT measurements due to deaths, move, serious illness or time constraints. After two cases were removed due to incomplete baseline data, the final study population consisted of 1149 participants.

Measurements of carotid IMT were conducted using a SonoSite MicroMaxx ultrasound machine (SonoSite, Inc., Bothell, WA, USA) equipped with an L38e/10-5 MHz transducer. All carotid imaging and IMT measurements were performed by a single physician who was trained and certified to perform carotid ultrasound measurements according to the specific ultrasound imaging and reading protocols developed, implemented and validated in the Oral Infections and Vascular Disease Epidemiology Study (INVEST) ${ }^{(33)}$. The carotid arteries were scanned longitudinally in three carotid segments, using the optimal angle and the lateral extent of each carotid segment as defined relative to the tip of the flow divider, which is normally the most clearly defined anatomic reference in the proximity of the carotid bifurcation. IMT measurements were analysed offline with Matlab (Mathworks, Natick, MA, USA), which automatically calculated the distances between boundaries and expressed the results as the mean and maximal value. In accordance with the Manheim consensus, we used the mean of the near and far walls of the maximum common carotid artery IMT from both sides of the neck (mean of four measurements) as the main outcome variable, similar to previous studies ${ }^{(34-36)}$.

\section{Assessment of covariates}

All covariates were derived from the HEALS baseline interview. Sociodemographic factors utilized in the current analysis included age, sex, formal education (years), land ownership (yes/no), television ownership (yes/no), smoking (never, former or current), diabetes history and religious affiliation (Muslim, Hindu, Christian, other). With respect to tobacco, details of cigarettes and bidis (filterless locally produced cigarettes) were asked together, including information on past or current use, duration of use, age at start, number of sticks per day and age at quitting. Trained study physicians measured height and weight using a locally manufactured tape measure and a Misaki (Okaka, Japan) scale (calibrated weekly), respectively. Both height and weight were measured three times at baseline and averaged ${ }^{(21)}$. Trained clinicians measured blood pressure with an automatic sphygmomanometer ${ }^{(22)}$. Measurements were taken with participants in a seated position after 5 min of rest, with the cuff around the upper left arm, in accordance with recommended guidelines. BMI was calculated as [average weight (kg)]/[average height $(\mathrm{m})]^{2}$. While other data were collected at baseline, we selected the aforementioned variables in particular as they were deemed most relevant to cardiovascular risk factor analysis. Data on physical activity, lipids and female menopause status were not available.

\section{Statistical analyses}

Descriptive analyses were conducted first to assess relationships of population characteristics and dietary intake with carotid IMT. Significance testing was conducted using the $\chi^{2}$ test for categorical variables and ANOVA for continuous variables. Continuous variables included carotid IMT, age, BMI, education, blood pressure and energy intake. Sex, cigarette use, diabetes, food group intake and dietary pattern adherence were assessed as categorical variables. The primary analysis evaluated the relationship between IMT and major food groups as well as dietary patterns. For this, linear regression was used, with dietary elements and patterns in quartiles as independent variables and common carotid IMT as the dependent variable. Quartiles of food groups were formed with respect to the combined cohort, as intake was recorded on an absolute scale. Due to relatively low levels of red meat and poultry consumption, all those with zero intake were grouped into the reference (first) quartile and individuals with non-zero intakes were then divided into the remaining higher quartiles. Because dietary patterns were derived separately in the original and expansion cohorts, cohortspecific quartiles for dietary patterns were used in the analyses. In the first model, we adjusted for age (years), sex, daily energy intake and smoking status (ever/never). Additional adjustment for educational attainment did not 
change results appreciably (data not shown). Subsequent models adjusted for BMI, blood pressure and diabetes mellitus (models 2 and 3). Physical activity metrics were not available for integration into these final models. IMT differences associated with a 1 SD difference in food groups and dietary pattern were computed for all models. Sensitivity analyses were conducted after excluding thirtyfive participants with history (prior to date of IMT) of CHD or stroke to minimize the potential for reverse causality (i.e. dietary changes resulted from life-changing atherosclerotic cardiovascular events). All analysis was conducted using the statistical software package IBM SPSS Statistics version 20 .

\section{Results}

Table 1 shows the distribution of dietary intakes and study population characteristics by carotid IMT quartile. Participants with a greater IMT measurement were more likely to be older $(P<0 \cdot 01)$. A positive correlation was seen between BMI and IMT $(P=0 \cdot 05)$. It is noteworthy that this population displayed a relatively low BMI, with a group mean of $19.95 \mathrm{~kg} / \mathrm{m}^{2}$ at baseline; diabetes differed significantly by quartile $(P<0 \cdot 01)$, with baseline prevalence in the highest quartile equal to $4.1 \%$ (compared with $1.0 \%$ in the lowest quartile). The only food group or dietary pattern to achieve significance in descriptive analysis was the animal protein diet, as the percentage above the median intake of that pattern increased steadily from the first to fourth quartile ( $42.9 \%$ to $61.5 \%$, respectively).

The animal protein diet was positively associated with a variety of markers of socio-economic status, as shown in Table 2 . These included educational attainment $(P<0 \cdot 01)$, television ownership $(P<0 \cdot 01)$, land ownership $(P<0 \cdot 01)$ and BMI $(P<0 \cdot 01)$. The gourd/root vegetable pattern was inversely related to both smoking $(P<0 \cdot 01)$ and male sex $(P<0 \cdot 01)$.

There was a significant difference $(P<0.01)$ in carotid IMT between men (mean IMT 822.06 $\mu \mathrm{m}$ ) and women (769.36 $\mu \mathrm{m}$; Appendix Table 3). As expected, blood pressure showed a strong positive correlation with IMT $(P<0.01)$. Although the population was relatively lean, BMI positively correlated with IMT as well $(P<0 \cdot 01)$.

The balanced diet was associated with lower IMT in the fully adjusted model, with each 1 SD increase in balanced diet adherence associated with a 4.95 (95\% CI -9.78, -0.11) $\mu \mathrm{m}$ decrease in IMT $(P=0.045$; Table 3$)$. In model 1 , each $1 \mathrm{SD}$ increase in adherence to the animal protein diet

Table 1 Distribution of dietary intakes and baseline population characteristics by carotid IMT quartile; Health Effects of Arsenic Longitudinal Study, rural Bangladesh

\begin{tabular}{|c|c|c|c|c|c|c|}
\hline & & Quartile 1 & Quartile 2 & Quartile 3 & Quartile 4 & \\
\hline & $\begin{array}{l}\text { Overall } \\
(n \text { 1149) }\end{array}$ & $\begin{array}{c}(557.5-717.4 \mu \mathrm{m} \\
n \text { 289) }\end{array}$ & $\begin{array}{c}(717.5-769.9 \mu \mathrm{m} \\
n 291)^{*}\end{array}$ & $\begin{array}{c}(770 \cdot 0-839.9 \mu \mathrm{m} \\
n 278)\end{array}$ & $\begin{array}{c}(840.0-1242.5 \mu \mathrm{m} \\
n 291) \dagger\end{array}$ & $P \neq$ \\
\hline \multicolumn{7}{|l|}{ Variables at the time of IMT assessment } \\
\hline Carotid IMT $(\mu \mathrm{m})$ & $789 \cdot 4$ & $682 \cdot 8$ & $745 \cdot 0$ & $802 \cdot 0$ & $927 \cdot 7$ & \\
\hline Age at IMT measurement (years) & 45.5 & 39.7 & 43.6 & $46 \cdot 7$ & $52 \cdot 0$ & $<0.01$ \\
\hline \multicolumn{7}{|l|}{ Baseline characteristics } \\
\hline Men (\%) & $38 \cdot 0$ & $22 \cdot 1$ & $36 \cdot 4$ & 37.4 & $56 \cdot 0$ & $<0.01$ \\
\hline BMI $\left(\mathrm{kg} / \mathrm{m}^{2}\right)$ & $20 \cdot 0$ & 19.5 & $20 \cdot 1$ & $20 \cdot 1$ & $20 \cdot 1$ & 0.05 \\
\hline Past or current cigarette use (\%) & 34.5 & $17 \cdot 6$ & $30 \cdot 2$ & $35 \cdot 3$ & $54 \cdot 6$ & $<0.01$ \\
\hline Educational attainment (years) & 3.0 & 3.2 & 2.9 & 3.2 & 2.8 & 0.56 \\
\hline History of diabetes (\%) & 1.8 & 1.0 & 0.3 & 1.8 & $4 \cdot 1$ & $<0.01$ \\
\hline Systolic blood pressure $(\mathrm{mmHg})$ & $117 \cdot 6$ & 112.5 & $115 \cdot 1$ & 118.5 & 124.4 & $<0.01$ \\
\hline Diastolic blood pressure $(\mathrm{mmHg})$ & $75 \cdot 7$ & 73.8 & 74.0 & $76 \cdot 3$ & 78.5 & $<0.01$ \\
\hline Total energy intake (MJ/d) & $10 \cdot 35$ & $10 \cdot 11$ & $10 \cdot 48$ & $10 \cdot 54$ & $10 \cdot 27$ & 0.29 \\
\hline Total energy intake $(\mathrm{kcal} / \mathrm{d})$ & 2473.6 & $2416 \cdot 8$ & 2505.6 & 2518.5 & 2454.9 & 0.29 \\
\hline \multicolumn{7}{|l|}{ Baseline food intake or pattern adherence } \\
\hline Red meat intake (\% above median) & $14 \cdot 2$ & 14.5 & 13.4 & 11.5 & $17 \cdot 2$ & 0.27 \\
\hline Poultry intake ( $\%$ above median) & $5 \cdot 0$ & 3.8 & 6.9 & 4.0 & $5 \cdot \overline{5}$ & 0.29 \\
\hline Fish intake ( $\%$ above median) & $47 \cdot 3$ & $44 \cdot 3$ & $50 \cdot 9$ & $46 \cdot 4$ & $47 \cdot 4$ & 0.45 \\
\hline Fruit intake (\% above median) & $50 \cdot 0$ & $45 \cdot 3$ & $50 \cdot 9$ & 53.2 & 50.5 & 0.28 \\
\hline Vegetable intake (\% above median) & $50 \cdot 0$ & $48 \cdot 1$ & $48 \cdot 1$ & 55.4 & 48.5 & 0.23 \\
\hline $\begin{array}{l}\text { Balanced diet adherence (\% above } \\
\text { median) }\end{array}$ & $50 \cdot 0$ & $46 \cdot 7$ & $54 \cdot 6$ & $52 \cdot 5$ & $46 \cdot 0$ & 0.10 \\
\hline $\begin{array}{l}\text { Animal protein diet adherence } \\
\text { (\% above median) }\end{array}$ & $50 \cdot 0$ & $42 \cdot 9$ & $46 \cdot 4$ & 48.9 & 61.5 & $<0.01$ \\
\hline $\begin{array}{l}\text { Gourd/root vegetable diet adherence } \\
\text { (\% above median) }\end{array}$ & $50 \cdot 0$ & 46.0 & 50.5 & 52.5 & 50.9 & 0.45 \\
\hline
\end{tabular}

IMT, intima-media thickness.

*Blood pressure measurements were not valid for two study participants.

†Blood pressure measurements were not valid for one study participant.

$\ddagger$ The $x^{2}$ test was used for categorical variables and ANOVA for continuous variables. 
was associated with an increase of 7.70 (95\% CI 2.45 , 12.95) $\mu \mathrm{m}$ in IMT. This association, however, did not persist in the fully adjusted model $(P=0.45)$. In all models, the gourd/root vegetable diet was strongly associated with increased IMT. Compared with participants in the bottom quartile of the gourd/root vegetable diet, IMT in participants in the second, third and fourth quartile was higher by $4.41(95 \%$ CI $-8.95,17.77) \mu \mathrm{m}, 14.77$ (95\% CI 1.33 , $28.22) \mu \mathrm{m}$ and $17.66(95 \% \mathrm{CI} 3.97,31.35) \mu \mathrm{m}$, respectively (model 3). IMT increase per 1 SD equalled 7.74 (95\% CI $2 \cdot 86,12.62) \mu \mathrm{m}$ in the fully adjusted model $(P<0.01)$. Sensitivity analyses excluding those with a history of CHD or stroke yielded very similar results (data not shown). It is noteworthy that, in contrast to the relationships observed in dietary pattern analysis, our data did not suggest that intakes of individual food groups were significantly related to IMT in this study population.

Shown in Table 4 are the Spearman correlation coefficients between nutrient intakes and factor scores for dietary patterns, which signify adherence to each respective diet. Among all of the patterns, the balanced diet was more positively correlated with $\mathrm{K}$, fibre, folate and vitamin $\mathrm{B}_{6}$; conversely, it was least correlated with polyunsaturated fat. The animal protein diet was highest in association with protein, $\mathrm{Na}$, total fat, vitamin $\mathrm{B}_{12}$, polyunsaturated fat, saturated fat, monounsaturated fat and riboflavin, while correlating least with carbohydrate, fibre, folate and $\mathrm{Mg}$. The gourd/root vegetable pattern was related to higher intake of carbohydrate and $\mathrm{Mg}$; of the diets, it was least associated with protein, $\mathrm{K}, \mathrm{Na}$, total fat, vitamin $\mathrm{B}_{6}$, vitamin $\mathrm{B}_{12}$, saturated fat, monounsaturated fat and riboflavin.

\section{Discussion}

Our data support a positive association of a gourd/root vegetable diet and IMT level $(7.74 \mu \mathrm{m}$ increase in model 3 ; $P<0 \cdot 01)$. Additionally, adherence to the balanced diet was associated with lower IMT ( $4.95 \mu \mathrm{m}$ decrease in model 3; $P=0.045$ ). Although single food groups were also measured in the study (meat, poultry, fish, fruit, vegetables), none displayed a statistically significant relationship with IMT. Given the high prevalence of CVD and considering that prior studies have shown clinically relevant differences in morbidity and mortality corresponding to IMT increases of 8 to $40 \mu \mathrm{m}$ (albeit in studies of varying design types $)^{(37-40)}$, the associations observed here could translate to substantial alterations in disease burden.

Many studies have provided evidence of certain foods or nutrients either enhancing or mitigating CVD risk ${ }^{(41)}$; however, individuals do not consume these dietary components in isolation. Dietary pattern analysis, although reliant on unique characteristics of food consumption in a given population that may limit generalizability of subsequent findings, can yield valuable information that may 


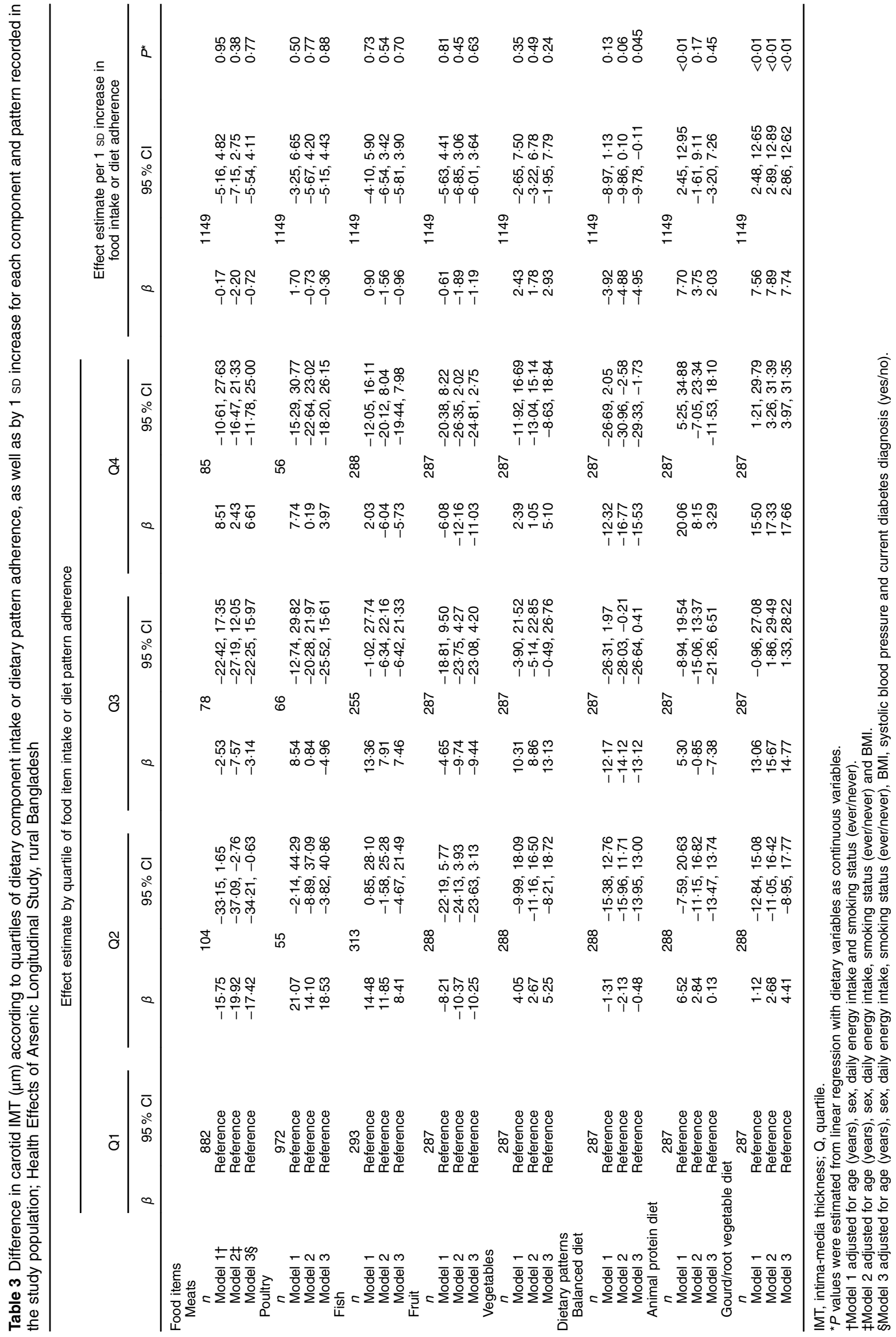


Table 4 Spearman correlations between factor scores for dietary patterns and daily nutrient intakes; Health Effects of Arsenic Longitudinal Study, rural Bangladesh

\begin{tabular}{lrrr}
\hline & \multicolumn{3}{c}{ Factor scores } \\
\cline { 2 - 4 } Average daily intake & & $\begin{array}{c}\text { Animal } \\
\text { protein } \\
\text { adjusted for total energy } \\
\text { intake }\end{array}$ & $\begin{array}{c}\text { Gourd/root } \\
\text { valanced } \\
\text { pattern } \\
\text { pattern }\end{array}$ \\
\hline Protein $(\mathrm{g})$ & 0.36 & 0.52 & 0.05 \\
Carbohydrate $(\mathrm{g})$ & -0.21 & -0.52 & 0.05 \\
$\mathrm{~K}(\mathrm{mg})$ & 0.63 & 0.39 & 0.28 \\
Na (mg) & 0.16 & 0.58 & 0.15 \\
Total fat $(\mathrm{g})$ & 0.21 & 0.61 & -0.06 \\
Fibre $(\mathrm{g})$ & 0.42 & 0.17 & 0.32 \\
Folate $(\mathrm{g})$ & 0.59 & 0.30 & 0.31 \\
Vitamin $\mathrm{B}_{6}(\mathrm{mg})$ & 0.63 & 0.13 & 0.09 \\
Vitamin $\mathrm{B}_{12}(\mathrm{mg})$ & 0.34 & 0.47 & -0.02 \\
Polyunsaturated fat $(\mathrm{g})$ & -0.16 & 0.62 & -0.01 \\
Saturated fat $(\mathrm{g})$ & 0.19 & 0.61 & -0.06 \\
Monounsaturated fat $(\mathrm{g})$ & 0.10 & 0.54 & -0.10 \\
Riboflavin (mg) & 0.51 & 0.64 & 0.16 \\
Mg (mg) & -0.12 & -0.51 & 0.20 \\
\hline
\end{tabular}

have otherwise been clouded in studies of single foods or nutrients. Indeed this was the case in the present study, as individual food groups did not alone convey any significant impact on IMT. Previous research on diet patterns and IMT, however, is limited, with one prior study finding no association for any diets identified in a middle-aged French population ${ }^{(42)}$ and another finding significance only among men (but not women) in comparing 'traditional' and 'health-conscious' diets among a population of Finns below the age of 40 years $^{(17)}$.

Atherosclerosis is an inflammatory phenomenon that is an important pathological process in the development of ischaemic CVD ${ }^{(43)}$. It has been hypothesized that certain diet choices can lead to a chronic inflammatory state, predisposing to atherosclerosis and increasing subsequent risk of cardiovascular morbidity and mortality ${ }^{(44)}$. Our findings regarding the balanced diet in this population are largely consistent with existing nutrition literature on atherosclerotic development, as 'cardioprotective' diets have been described as being high in vegetables, nuts and monounsaturated fats ${ }^{(44-46)}$, while 'harmful' factors include trans-fatty acids, foods with a high glycaemic index, processed meats, refined grains and high-fat foods ${ }^{(45,47)}$. This is illustrated in Table 4 where the balanced pattern corresponds with a lower intake of both saturated fat and total fat, as well as in Appendix Table 1, where the balanced pattern is shown to de-emphasize animal protein and integrate a wider variety of vegetables when compared with the animal protein pattern.

The findings presented here are consistent with some aspects our previously published data on risk of cardiovascular mortality associated with these same three dietary patterns in the parent HEALS study population ${ }^{(31)}$. For example, we found borderline significantly reduced risk of CVD and heart disease associated with the balanced diet pattern (hazard ratio $=0.86 ; 95 \%$ CI $0.73,1.01$ ) that was associated with decreased IMT in the present study $(P=0.045)$. Likewise, although the observed positive association between the animal protein diet and IMT was not statistically significant, the data were consistent with our previous analyses that reported an increased risk of mortality found for the animal protein diet (hazard ratio $=1 \cdot 13 ; 95 \%$ CI $1.00,1 \cdot 28)$. The gourd/root vegetable diet, although associated with higher IMT here $(P<0 \cdot 01)$, was not related to risk of mortality in our prior analysis (hazard ratio $=1 \cdot 03 ; 95 \%$ CI $0 \cdot 89,1 \cdot 18$ ). It is possible that the lack of agreement between findings of the present study and some of the mortality results may be due to the fact that we focus on a single preclinical indicator of atherosclerosis and, therefore, may not capture the full complement of multifactorial, complex pathological processes that underlie the association of diet with cardiovascular morbidity and mortality.

The observation that a gourd and root vegetable diet in our population is related to higher levels of IMT contradicts what has been found in some recent studies of food patterns $^{(10,11,48)}$. For example, a recent series of studies comparing vegetarian and omnivore diets in Chinese men associated a vegetarian diet with decreased $\operatorname{IMT}^{(10,11)}$. It is crucial to note, however, that specific nutritional deficiencies may be present in certain types of vegetable-based diets and can predispose adherents to adverse health outcomes, especially in a lean population ${ }^{(49,50)}$. In particular, such diets may be lacking in certain $n$ - 3 fatty acids (namely EPA and DHA $)^{(50)}$ and vitamin $\mathrm{B}_{12}{ }^{(51,52)}$, which is obtained solely through consumption of animal products ${ }^{(53)}$. As a result, the nutrient deficiencies in such diets may negate the coinciding decreased fat intake that otherwise would have conveyed cardiovascular benefits. $\mathrm{B}_{12}$ insufficiency has been shown to be most widespread in developing countries ${ }^{(51,54)}$, with South Asian populations considered to be at uniquely high risk $^{(55)}$. Consistently, we have reported a high prevalence of hyperhomocysteinaemia in our study population $^{(56)}$. It should lastly be considered that the gourd/root vegetable diet was most highly associated with carbohydrate intake, which may increase atherosclerosis when such foods take the place of unsaturated fats ${ }^{(57)}$.

\section{Study limitations and strengths}

To our knowledge, the present study is the first of dietary patterns and IMT in a low-income country. Strengths of our study include its large, population-based sample size as well as use of a validated FFQ and standardized IMT protocols. Additionally, religious motivations lead to restricted alcohol consumption in Bangladesh and remove a potential confounder, as does the fact that a particularly small segment of the study population reported use of any prescription drugs at baseline. Excluding contraceptives, the most common prescriptions were ulcer/gastro-oesophageal reflux medications ( $4.31 \%$ of participants), antibiotics $(1.43 \%)$ and beta blockers $(0 \cdot 81 \%)^{(58)}$. Limitations include 
the cross-sectional study design, with a time gap between FFQ administration (during baseline enrolment periods: 2000-2002 or 2006-2008) and IMT measurement (2010-2011). Although the absence of IMT measurement at recruitment makes it impossible to firmly establish a temporal relationship, atherosclerosis is a chronic disease that is likely to develop over a long period of time as a result of past and persistent exposure. Our FFQ was validated to measure long-term usual levels of common foods and nutrients ${ }^{(24)}$; as such, further adjustment of our primary outcome models for recruitment period did not affect the significance of association in either the gourd/root vegetable or balanced diet $(P<0.01)$. An additional limitation is that although diet patterns can be argued to be a more effective, realistic method of assessing food consumption, their determination still involves some subjectivity. The findings presented here are also limited by our lack of data on physical activity and lipids, known determinants of CVD. We, likewise, have no data regarding the menopause status of female participants. Lastly, certain characteristics of the study population also limit generalizability, as the population possessed a mean age of 39 years at enrolment (range $17-65$ years) and a mean BMI of $19.95 \mathrm{~kg} / \mathrm{m}^{2}$ (range 11.70 $35 \cdot 58 \mathrm{~kg} / \mathrm{m}^{2}$ ).

\section{Conclusions}

In conclusion, we found a gourd/root vegetable diet to correlate with increased carotid IMT, while a balanced diet was associated with a decrease in IMT. These findings underscore the utility of whole dietary pattern analysis in identifying nutrient deficiencies associated with population-specific diets, and could be useful in determining the most effective strategies for chronic disease prevention in this and similar populations.

\section{Acknowledgements}

Financial support: This research was supported by the National Institutes of Health (grant numbers R01 ES017541, P42 ES010349 and P30 ES000260) and in part by the National Center for the Advancement of Translational Science (NCATS), National Institutes of Health (grant number UL1 TR000038). The National Institutes of Health had no role in the design, analysis or writing of this article. Conflict of interest: None. Authorship: Authorship for all individuals listed on this manuscript was justified through participation in the following: conception and design (T.R.M., Y.C., F.P., T.I., A.A., R.R.P., I.S., G.S., H.A.), data collection (F.P., T.I., A.A., R.R.P., I.S., G.S.), data management (F.P., T.I., A.A., R.R.P., I.S., G.S.), analysis and interpretation of data (T.R.M., Y.C., F.W., T.R., R.T.D., M.D., H.A.), drafting of the manuscript (T.R.M., Y.C.), revising the manuscript critically for important intellectual content (all authors) and final approval of the manuscript (all authors). Ethics of buman subject participation: Informed consent was obtained from study participants; study procedures were approved by the Ethical Committee of the Bangladesh Medical Research Council and the Institutional Review Boards of Columbia University and the University of Chicago.

\section{References}

1. Yusuf S, Reddy S, Ounpuu S et al. (2001) Global burden of cardiovascular diseases - Part I: General considerations, the epidemiologic transition, risk factors, and impact of urbanization. Circulation 104, 2746-2753.

2. Lopez AD \& Mathers CD (2006) Measuring the global burden of disease and epidemiological transitions: 2002-2030. Ann Trop Med Parasitol 100, 481-499.

3. Perk J, De Backer G, Gohlke H et al. (2012) European Guidelines on cardiovascular disease prevention in clinical practice (version 2012). The Fifth Joint Task Force of the European Society of Cardiology and Other Societies on Cardiovascular Disease Prevention in Clinical Practice (constituted by representatives of nine societies and by invited experts). Developed with the special contribution of the European Association for Cardiovascular Prevention \& Rehabilitation (EACPR). Eur Heart J 33, 1635-1701.

4. Reddy KS \& Yusuf S (1998) Emerging epidemic of cardiovascular disease in developing countries. Circulation 97, 596-601.

5. Omran AR (1971) Epidemiologic transition - theory of epidemiology of population change. Milbank Mem Fund $Q$ 49, 509-538.

6. Islam M (2011) Mortality and epidemiological transition in Bangladesh: lessons and experiences to the developing countries in the new millennium. J Epidemiol Commun Health 65, A116.

7. Stein JH, Korcarz CE, Hurst RT et al. (2008) Use of carotid ultrasound to identify subclinical vascular disease and evaluate cardiovascular disease risk: a consensus statement from the American Society of Echocardiography Carotid Intima-Media Thickness Task Force. Endorsed by the Society for Vascular Medicine. J Am Soc Echocardiogr 21, 93-111.

8. Nettleton JA, Schulze MB, Jiang R et al. (2008) A prioridefined dietary patterns and markers of cardiovascular disease risk in the Multi-Ethnic Study of Atherosclerosis (MESA). Am J Clin Nutr 88, 185-194.

9. Buil-Cosiales P, Irimia P, Ros E et al. (2009) Dietary fibre intake is inversely associated with carotid intima-media thickness: a cross-sectional assessment in the PREDIMED study. Eur J Clin Nutr 63, 1213-1219.

10. Yang SY, Li XJ, Zhang W et al. (2012) Chinese lactovegetarian diet exerts favorable effects on metabolic parameters, intima-media thickness, and cardiovascular risks in healthy men. Nutr Clin Pract 27, 392-398.

11. Yang SY, Zhang HJ, Sun SY et al. (2011) Relationship of carotid intima-media thickness and duration of vegetarian diet in Chinese male vegetarians. Nutr Metab (Lond) 8, 63.

12. Wildman RP, Schott LL, Brockwell S et al. (2004) A dietary and exercise intervention slows menopause-associated progression of subclinical atherosclerosis as measured by intima-media thickness of the carotid arteries. $\mathrm{J} \mathrm{Am} \mathrm{Coll}$ Cardiol 44, 579-585.

13. Agewall S, Fagerberg B, Berglund G et al. (2001) Multiple risk intervention trial in high risk hypertensive men: comparison of ultrasound intima-media thickness and clinical outcome during 6 years of follow-up. J Intern Med $\mathbf{2 4 9}$, 305-314. 
14. Murie-Fernandez M, Irimia P, Toledo E et al. (2011) Carotid intima-media thickness changes with Mediterranean diet: a randomized trial (PREDIMED-Navarra). Atherosclerosis 219 , 158-162.

15. Sala-Vila A, Romero-Mamani ES, Gilabert R et al. (2014) Changes in ultrasound-assessed carotid intima-media thickness and plaque with a Mediterranean diet: a substudy of the PREDIMED trial. Arterioscler Thromb Vasc Biol 34, 439-445.

16. Gardener H, Wright CB, Cabral D et al. (2014) Mediterranean diet and carotid atherosclerosis in the Northern Manhattan Study. Atherosclerosis 234, 303-310.

17. Mikkila V, Rasanen L, Laaksonen MM et al. (2009) Longterm dietary patterns and carotid artery intima media thickness: the Cardiovascular Risk in Young Finns Study. BrJ Nutr 102, 1507-1512.

18. Hu FB (2002) Dietary pattern analysis: a new direction in nutritional epidemiology. Curr Opin Lipidol 13, 3-9.

19. Willett WC (1994) Diet and health - what should we eat. Science 264, 532-537.

20. Ahsan H, Chen Y, Parvez F et al. (2006) Health Effects of Arsenic Longitudinal Study (HEALS): description of a multidisciplinary epidemiologic investigation. J Expo Sci Environ Epidemiol 16, 191-205.

21. Pierce BL, Kalra T, Argos M et al. (2010) A prospective study of body mass index and mortality in Bangladesh. Int $J$ Epidemiol 39, 1037-1045.

22. Chen Y, Factor-Litvak P, Howe GR et al. (2006) Nutritional influence on risk of high blood pressure in Bangladesh: a population-based cross-sectional study. Am J Clin Nutr 84, 1224-1232.

23. Wu F, Chen Y, Parvez F et al. (2013) A prospective study of tobacco smoking and mortality in Bangladesh. PLoS One $\mathbf{8}$, e58516.

24. Chen Y, Ahsan H, Parvez F et al. (2004) Validity of a foodfrequency questionnaire for a large prospective cohort study in Bangladesh. Br J Nutr 92, 851-859.

25. US Department of Agriculture ARS (2002) USDA National Nutrient Database for Standard Reference, Release 15. http:// www.ars.usda.gov/Services/docs.htm?docid=8964 (accessed August 2006).

26. Gopalan C, Rama Sastri BV \& Balasubramanian SC (1989) Nutritive Value of Indian Foods. Hyderabad: National Institute of Nutrition, Indian Council of Medical Research.

27. Willett WC, Sampson L, Stampfer MJ et al. (1985) Reproducibility and validity of a semiquantitative food frequency questionnaire. Am J Epidemiol 122, 51-65.

28. Erkkola M, Karppinen M, Javanainen J et al. (2001) Validity and reproducibility of a food frequency questionnaire for pregnant Finnish women. Am J Epidemiol 154, 466-476.

29. Hatcher L (1994) A Step-by-Step Approach to Using the SAS System for Factor Analysis and Structural Equation Modeling. Cary, NC: SAS Institute.

30. Pierce BL, Argos M, Chen Y et al. (2011) Arsenic exposure, dietary patterns, and skin lesion risk in Bangladesh: a prospective study. Am J Epidemiol 173, 345-354.

31. Chen Y, McClintock TR, Segers S et al. (2013) Prospective investigation of major dietary patterns and risk of cardiovascular mortality in Bangladesh. Int J Cardiol 167, 1495-1501.

32. Chen Y, Hakim ME, Parvez F et al. (2006) Arsenic exposure from drinking-water and carotid artery intima-medial thickness in healthy young adults in Bangladesh. J Health Popul Nutr 24, 253-257.

33. Desvarieux M, Demmer RT, Rundek T et al. (2005) Periodontal microbiota and carotid intima-media thickness: the Oral Infections and Vascular Disease Epidemiology Study (INVEST). Circulation 111, 576-582.

34. O'Leary DH, Polak JF, Kronmal RA et al. (1999) Carotidartery intima and media thickness as a risk factor for myocardial infarction and stroke in older adults. Cardiovascular Health Study Collaborative Research Group. N Engl J Med 340, 14-22.
35. Kitamura A, Iso H, Imano $\mathrm{H}$ et al. (2004) Carotid intima-media thickness and plaque characteristics as a risk factor for stroke in Japanese elderly men. Stroke 35, 2788-2794.

36. Touboul PJ, Hennerici MG, Meairs S et al. (2012) Mannheim carotid intima-media thickness and plaque consensus (2004-2006-2011). An update on behalf of the advisory board of the $3 \mathrm{rd}$, 4th and 5 th watching the risk symposia, at the 13th, 15th and 20th European Stroke Conferences, Mannheim, Germany, 2004, Brussels, Belgium, 2006, and Hamburg, Germany, 2011. Cerebrovasc Dis 34, 290-296.

37. Zureik M, Touboul PJ, Bonithon-Kopp C et al. (1999) Crosssectional and 4-year longitudinal associations between brachial pulse pressure and common carotid intima-media thickness in a general population. The EVA study. Stroke 30, $550-555$

38. Ando F, Takekuma K, Niino N et al. (2000) Ultrasonic evaluation of common carotid intima-media thickness (IMT) - influence of local plaque on the relationship between IMT and age. J Epidemiol 10, 1 Suppl., S10-S17.

39. Hodis HN, Mack WJ, LaBree L et al. (1998) The role of carotid arterial intima-media thickness in predicting clinical coronary events. Ann Intern Med 128, 262-269.

40. Crouse JR 3rd, Byington RP, Bond MG et al. (1995) Pravastatin, Lipids, and Atherosclerosis in the Carotid Arteries (PLAC-II). Am J Cardiol 75, 455-459.

41. Mozaffarian D, Appel LJ \& Van Horn L (2011) Components of a cardioprotective diet: new insights. Circulation $\mathbf{1 2 3}$, 2870-2891.

42. Kesse-Guyot E, Vergnaud AC, Fezeu L et al. (2010) Associations between dietary patterns and arterial stiffness, carotid artery intima-media thickness and atherosclerosis. Eur J Cardiovasc Prev Rehabil 17, 718-724.

43. Ross R (1999) Atherosclerosis - an inflammatory disease. $N$ Engl J Med 340, 115-126.

44. De Caterina R, Zampolli A, Del Turco S et al. (2006) Nutritional mechanisms that influence cardiovascular disease. Am J Clin Nutr 83, issue 2, 421S-426S.

45. Mente A, de Koning L, Shannon HS et al. (2009) A systematic review of the evidence supporting a causal link between dietary factors and coronary heart disease. Arch Intern Med 169, 659-669.

46. Millen BE, Quatromoni PA, Nam BH et al. (2002) Dietary patterns and the odds of carotid atherosclerosis in women: the Framingham Nutrition Studies. Prev Med 35, 540-547.

47. Nettleton JA, Steffen LM, Schulze MB et al. (2007) Associations between markers of subclinical atherosclerosis and dietary patterns derived by principal components analysis and reduced rank regression in the Multi-Ethnic Study of Atherosclerosis (MESA). Am J Clin Nutr 85, 1615-1625.

48. Key TJ, Fraser GE, Thorogood M et al. (1999) Mortality in vegetarians and nonvegetarians: detailed findings from a collaborative analysis of 5 prospective studies. Am J Clin Nutr 70, 3 Suppl., 516S-524S.

49. Lee HY, Woo J, Chen ZY et al. (2000) Serum fatty acid, lipid profile and dietary intake of Hong Kong Chinese omnivores and vegetarians. Eur J Clin Nutr 54, 768-773.

50. Davis BC \& Kris-Etherton PM (2003) Achieving optimal essential fatty acid status in vegetarians: current knowledge and practical implications. Am J Clin Nutr 78, 3 Suppl., 640S-646S.

51. Ingenbleek Y \& McCully KS (2012) Vegetarianism produces subclinical malnutrition, hyperhomocysteinemia and atherogenesis. Nutrition 28, 148-153.

52. Siri PW, Verhoef P \& Kok FJ (1998) Vitamins $\mathrm{B}_{6}, \mathrm{~B}_{12}$, and folate: association with plasma total homocysteine and risk of coronary atherosclerosis. J Am Coll Nutr 17, 435-441.

53. Green R \& Kinsella LJ (1995) Current concepts in the diagnosis of cobalamin deficiency. Neurology 45, 1435-1440.

54. Yajnik CS, Deshpande SS, Lubree HG et al. (2006) Vitamin $\mathrm{B}_{12}$ deficiency and hyperhomocysteinemia in rural and urban Indians. J Assoc Physicians India 54, 775-782. 
55. Gammon CS, von Hurst PR, Coad J et al. (2012) Vegetarianism, vitamin $\mathrm{B}_{12}$ status, and insulin resistance in a group of predominantly overweight/obese South Asian women. Nutrition 28, 20-24.

56. Gamble MV, Ahsan H, Liu X et al. (2005) Folate and cobalamin deficiencies and hyperhomocysteinemia in Bangladesh. Am J Clin Nutr 81, 1372-1377.
57. Mozaffarian D, Rimm EB \& Herrington DM (2004) Dietary fats, carbohydrate, and progression of coronary atherosclerosis in postmenopausal women. Am J Clin Nutr 80, 1175-1184.

58. Scannell M, Argos M, Pierce B et al. (2013) Cross-sectional study of the predictors of medication use, hypertension prevalence, and hypertension treatment in Bangladeshi adults. Am J Epidemiol 177, Suppl. 11, S38.

Appendix Table 1 Composition of food groups

\begin{tabular}{|c|c|c|c|c|c|}
\hline & Meats & Poultry & Fish & Vegetables & Fruits \\
\hline \multicolumn{6}{|l|}{ Tea } \\
\hline Large fish (freshwater) & & & $\checkmark$ & & \\
\hline Poultry (fowl) & & $\checkmark$ & & & \\
\hline \multicolumn{6}{|l|}{ Eggs (hen eggs) } \\
\hline \multicolumn{6}{|l|}{ Milk } \\
\hline \multicolumn{6}{|l|}{ Puffed rice } \\
\hline \multicolumn{6}{|l|}{ Wheat bread (brown) } \\
\hline Beef or mutton & $\checkmark$ & & & & \\
\hline Bitter gourd* & & & & $\checkmark$ & \\
\hline \multicolumn{5}{|l|}{ Banana } & $\checkmark$ \\
\hline \multicolumn{6}{|l|}{ Jack fruit } \\
\hline \multicolumn{6}{|l|}{ Watermelon } \\
\hline \multicolumn{6}{|l|}{ Mango } \\
\hline \multicolumn{6}{|l|}{ Steamed rice } \\
\hline Guava & & & & & $\checkmark$ \\
\hline \multicolumn{6}{|l|}{ Potato } \\
\hline \multicolumn{6}{|l|}{ Small fish (freshwater) } \\
\hline \multicolumn{6}{|l|}{$\begin{array}{l}\text { Tomato } \\
\text { Bottle gourd* }\end{array}$} \\
\hline \multicolumn{6}{|l|}{ Bottle gourd ${ }^{*}$} \\
\hline \multicolumn{6}{|l|}{ Beans (scarlet runner) } \\
\hline \multicolumn{6}{|l|}{ Eggplant } \\
\hline \multicolumn{6}{|l|}{ Parwar or patol* } \\
\hline \multicolumn{6}{|l|}{ Green papaya } \\
\hline \multicolumn{6}{|l|}{ Cabbage } \\
\hline \multicolumn{6}{|l|}{ Okra } \\
\hline \multicolumn{6}{|l|}{ Yam } \\
\hline \multicolumn{6}{|l|}{ Spinach } \\
\hline \multicolumn{6}{|l|}{ Cauliflower } \\
\hline \multicolumn{6}{|l|}{ Sweet potato } \\
\hline \multirow{2}{*}{\multicolumn{6}{|c|}{$\begin{array}{l}\text { Dried fish } \\
\text { Water rice }\end{array}$}} \\
\hline & & & & & \\
\hline \multicolumn{6}{|l|}{ Ridge gourd or jhinga* } \\
\hline \multicolumn{6}{|l|}{ Snake gourd or chachinga* } \\
\hline Ghosala or dhundal* & & & & $\checkmark$ & \\
\hline Radish & & & & $\checkmark$ & \\
\hline Spinach stalks & & & & $\checkmark$ & \\
\hline Pumpkin & & & & $\checkmark$ & \\
\hline Salted fish & & & $\checkmark$ & & \\
\hline
\end{tabular}

${ }^{*}$ A kind of squash. 
Appendix Table 2 Factor loading matrix for dietary patterns derived from principal component analysis*

\begin{tabular}{|c|c|c|c|c|c|c|}
\hline \multirow[b]{2}{*}{ Food item } & \multicolumn{3}{|c|}{ Original cohort } & \multicolumn{3}{|c|}{ Expansion cohort } \\
\hline & $\begin{array}{c}\text { Balanced } \\
\text { pattern }\end{array}$ & $\begin{array}{l}\text { Animal protein } \\
\text { pattern }\end{array}$ & $\begin{array}{c}\text { Gourd/root } \\
\text { vegetable pattern }\end{array}$ & $\begin{array}{c}\text { Balanced } \\
\text { pattern }\end{array}$ & $\begin{array}{l}\text { Animal protein } \\
\text { pattern }\end{array}$ & $\begin{array}{c}\text { Gourd/root } \\
\text { vegetable pattern }\end{array}$ \\
\hline Tea & & 0.48 & & & 0.55 & \\
\hline Large fish (freshwater) & & 0.44 & & & 0.42 & \\
\hline Poultry (fowl) & & 0.47 & & & 0.50 & \\
\hline Lentil & & 0.37 & & & 0.41 & 0.16 \\
\hline Eggs (hen eggs) & & 0.49 & & 0.27 & 0.44 & \\
\hline Milk & & 0.49 & & 0.24 & 0.43 & \\
\hline Puffed rice & & 0.22 & & 0.30 & & \\
\hline Wheat bread (brown) & -0.17 & 0.49 & & & 0.54 & \\
\hline Beef or mutton & 0.21 & 0.45 & & & 0.40 & \\
\hline Bitter gourd $\dagger$ & 0.42 & 0.18 & 0.28 & 0.44 & & 0.21 \\
\hline Banana & $0 \cdot 16$ & 0.47 & & 0.50 & 0.19 & \\
\hline Jack fruit & 0.30 & 0.22 & & 0.37 & & \\
\hline Watermelon & 0.20 & 0.29 & & 0.39 & 0.22 & \\
\hline Mango & 0.39 & 0.23 & & 0.41 & 0.21 & \\
\hline Steamed rice & 0.25 & -0.31 & & 0.36 & -0.16 & 0.36 \\
\hline Guava & 0.27 & & & 0.44 & & \\
\hline Potato & 0.22 & & & 0.26 & & \\
\hline Small fish (freshwater) & 0.39 & & & 0.36 & & \\
\hline Tomato & 0.70 & & & 0.35 & & 0.32 \\
\hline Bottle gourd $\dagger$ & 0.46 & & & 0.30 & & 0.38 \\
\hline Beans (scarlet runner) & 0.62 & & & 0.27 & & 0.42 \\
\hline Eggplant & 0.33 & & $0 \cdot 16$ & 0.44 & & \\
\hline Parwar or patol† & 0.22 & $0 \cdot 17$ & 0.37 & 0.27 & & 0.27 \\
\hline Green papaya & 0.22 & & 0.35 & 0.21 & & 0.17 \\
\hline Cabbage & 0.51 & & 0.25 & & & 0.55 \\
\hline Okra & 0.29 & & 0.37 & 0.25 & & 0.37 \\
\hline Yam & 0.31 & & 0.26 & & & 0.55 \\
\hline Spinach & 0.24 & & 0.26 & 0.47 & & \\
\hline Cauliflower & 0.64 & & 0.17 & & 0.16 & 0.59 \\
\hline Sweet potato & & & 0.29 & 0.25 & -0.27 & 0.16 \\
\hline Dried fish & & & 0.22 & & -0.28 & \\
\hline Water rice & & & $0 \cdot 17$ & & -0.33 & \\
\hline Ridge gourd or jhinga† & & & 0.53 & & & 0.44 \\
\hline Snake gourd or chachinga† & & & 0.57 & & & 0.55 \\
\hline Ghosala or dhundalt & & & 0.51 & & & 0.40 \\
\hline Radish & & & 0.48 & & & 0.66 \\
\hline Spinach stalks & & & 0.48 & & & 0.49 \\
\hline Pumpkin & & & 0.39 & 0.32 & & 0.24 \\
\hline Salted fish & & & & 0.24 & & \\
\hline
\end{tabular}

*Factor loadings represent the correlation between factor scores and intakes of food items. Positive factor loadings $\leq 0 \cdot 15$ and negative factor loadings $\geq-0 \cdot 15$ were omitted from the table for simplicity. Factor loadings presented are those that resulted from orthogonal rotation.

†A kind of squash. 
Appendix Table 3 Mean carotid IMT based on baseline characteristics of the study population; Health Effects of Arsenic Longitudinal Study, rural Bangladesh

\begin{tabular}{|c|c|c|c|c|}
\hline & $n$ & Mean carotid IMT $(\mu \mathrm{m})$ & $P^{\star}$ & Adjusted $P \dagger$ \\
\hline Sex & & & $<0.01$ & $<0.01$ \\
\hline Men & 437 & $822 \cdot 1$ & & \\
\hline Women & 712 & $769 \cdot 4$ & & \\
\hline Age at IMT measurement (years) & & & $<0.01$ & $<0.01$ \\
\hline$<35$ & 167 & $732 \cdot 0$ & & \\
\hline $35-49$ & 634 & 768.9 & & \\
\hline$\geq 50$ & 348 & 854.2 & & \\
\hline Education (years) & & & 0.66 & 0.02 \\
\hline$<5$ & 742 & $790 \cdot 2$ & & \\
\hline $5-9$ & 306 & $782 \cdot 7$ & & \\
\hline$\geq 10$ & 101 & $804 \cdot 1$ & & \\
\hline Smoking & & & $<0.01$ & 0.22 \\
\hline Never & 753 & $768 \cdot 3$ & & \\
\hline Past or current & 396 & $829 \cdot 6$ & & \\
\hline Blood pressure $(\mathrm{mmHg}) \ddagger$ & & & $<0.01$ & $<0.01$ \\
\hline$<120$ & 673 & 768.7 & & \\
\hline $120-139$ & 371 & $805 \cdot 8$ & & \\
\hline$\geq 140$ & 102 & $866 \cdot 2$ & & \\
\hline $\mathrm{BMI}\left(\mathrm{kg} / \mathrm{m}^{2}\right)$ & & & 0.01 & $<0.01$ \\
\hline$<18$ & 366 & $786 \cdot 1$ & & \\
\hline $18-20$ & 413 & 781.6 & & \\
\hline$\geq 21$ & 370 & 801.4 & & \\
\hline
\end{tabular}

IMT, intima-media thickness.

*Unadjusted linear regression models with carotid IMT as dependent variable.

†Linear regression models with carotid IMT as dependent variable; adjusted for all other variables in the table.

$\ddagger$ Systolic blood pressure; blood pressure measurements were not valid for three study participants. 